\title{
FABRIKASI KEMASAN AKSESORI ARSITEKTURAL UNTUK KELOMPOK PENGRAJIN KAMPUNG AMPERA
}

\author{
Rudy Trisno ${ }^{1}$, Clinton Thedyardi ${ }^{2}$ \\ ${ }^{1}$ Program Studi Arsitektur, Jurusan Arsitektur dan Perencanaan, Fakultas Teknik, Universitas Tarumanagara \\ Email: rudyt@ft.untar.ac.id \\ ${ }^{2}$ Program Studi Arsitektur, Jurusan Arsitektur dan Perencanaan, Fakultas Teknik, Universitas Tarumanagara \\ Email: clinton.thedyardi@gmail.com
}

\begin{abstract}
A community engagement activity was aimed at the craftsmen of Kampung Ampera to the UNTAR PKM Team to provide training in the fabrication of architectural accessory packaging supported by an invitation from a fashion designer for the needs of the Soiree event in Tulodong, South Jakarta. This event gives work to craftsmen to make packaging with transparent characters that have never been made by craftsmen before, plus the design is expected to have a high intellectual level and is a delicate work for the upper middle class target. Acrylic material is used as a fabrication material that is often used in fields and architectural work. The packaging is formed by cutting, laser cutting and bending machines to produce transparent packaging that accentuates the accessories for sale. The experimental method is used by adhering to the process of turning the material into the final result, using an acrylic cutting machine to produce bulk cuts with a high degree of fineness, and heaters for bending. The design sketch was developed through a series of tests on several architectural materials with transparent or translucent characters. Production, detailing and gluing are carried out by a group of craftsmen producing ready-to-sell packaging that was presented at the Soiree event and received good appreciation. The findings in this study are to improve human resources in Kampung Ampera to change the workings of making gold from manuals to the development of cad technology that is more precise and can be made in bulk, in accordance with the development of the Industrial Revolution 4.0.
\end{abstract}

Keywords: Accessories; Architectural; Fabrication; Packaging; Craftsman

\begin{abstract}
ABSTRAK
Sebuah kegiatan pengabdian kepada masyarakat ditujukan kepada pengrajin Kampung Ampera kepada Tim PKM UNTAR untuk memberikan pelatihan fabrikasi kemasan aksesori arsitektural didukung oleh undangan dari perancang busana untuk kebutuhan acara Soiree di Tulodong, Jakarta Selatan. Acara ini memberikan pekerjaan kepada pengrajin untuk membuat kemasan dengan karakter transparan yang belum pernah dibuat pengrajin sebelumnya, ditambah lagi rancangan diharapkan memiliki tingkat intelektual tinggi dan merupakan pekerjaan halus untuk target kalangan menengah atas. Material akrilik digunakan sebagai material fabrikasi yang kerap digunakan di bidang dan pekerjaan arsitektural. Kemasan dibentuk dengan mesin potong, laser cutting dan bending sehingga menghasilkan kemasan transparan yang menonjolkan aksesori yang dijual. Metode eksperimental digunakan dengan berpegang pada proses memalih material menjadi hasil akhir, menggunakan mesin potong akrilik untuk menghasilkan potongan massal dengan tingkat kehalusan tinggi, dan pemanas untuk bending. Sketsa rancangan dikembangkan melalui serangkaian tes terhadap beberapa material arsitektural berkarakter transparan atau translusen. Produksi, pendetailan dan pengeleman dilakukan oleh kelompok pengrajin menghasilkan kemasan siap jual yang dipresentasikan pada acara Soiree dan mendapatkan apresiasi baik. Temuan dalam penelitian ini adalah meningkatkan sumber daya manusia di Kampung Ampera untuk merubah cara kerja pembuatan keemasan dari manual ke perkembangan teknologi cad yang lebih presisi dan bisa dibuat secara massal, sesuai dengan perkembangan Revolusi Industri 4.0.
\end{abstract}

Kata kunci: Aksesori; Arsitektural; Fabrikasi; Kemasan; Pengrajin

\section{PENDAHULUAN}

Tim pengabdian masyarakat ini bermaksud mengembangkan kemampuan pengrajin dengan menitikberatkan pada fabrikasi arsitektural untuk pembuatan kemasan aksesoris untuk perancang busana di acara Soiree, Soiree adalah kegiatan untuk menjual produk PKM dan juga promosi untuk pengerajin untuk kalangan kelas menegah ke atas di Tulodong, Jakarta Selatan. Soiree mendukung 
konsep perancang busana melalui transparansi. Gagasan membuat kemasan transparan adalah salah satu ide yang menjadi tujuan utama untuk kemasan aksesori Soiree. Namun demikian material dan detail kemasan menjadi sulit dilakukan, karena sifat transparansi bahan mudah dikenali kecacatannya sehingga sambungan menjadi fokus utama membuat kemasan yang mendekati sempurna. Sebuah rancangan kemasan aksesoris sederhana diinisiasi dalam kegiatan ini untuk membuka peluang pembuatan kemasan aksesori dengan material yang tidak biasa dan fabrikasi yang belum pernah dicoba oleh pengrajin Kampung Ampera. Karya mereka direncanakan untuk dipamerkan dan dipromosikan kepada sesama perancang busana, klien-klien pada kelas menengah ke atas dan khalayak luas. Acara Soiree dapat membuka kesempatan bagi pengrajin menjadi tenaga kerja (Bloch, 2011). Namun demikian kebanyakan pengrajin Kampung Ampera berada pada situasi yang kurang kondusif untuk mengembangkan diri karena kerap menerima pekerjaan yang sama dan berkualitas relatif rendah. Sudah beberapa kali tawaran pekerjaan membuat kemasan ditolak oleh pengrajin Kampung Ampera, karena dirasa fabrikasi terlalu sulit dan membutuhkan keterampilan khusus. Padahal jenis pekerjaan seperti ini umumnya berbudget besar. Secara umum, pengrajin kampung Ampera mereplikasi produk kerajinan dan kemasan jadi dengan pola standar/umum daripada bekerja berdasar atas kreativitas (Grassby, 2005). Pengetahuan akan penggunaan bahan dan teknik fabrikasi arsitektural perlu dikembangkan agar dapat dikembangkan untuk variasi pekerjaan lainnya (Doğan, 2012).

Pada umumnya pengrajin kampung Ampera berada ditingkat ekonomi lemah dengan pendidikan rendah sehingga mengandalkan keterampilan. Keterbatasan ekonomi menekan mereka untuk sekedar bekerja pada teman atau tetangga, berdasarkan tawaran pekerjaan untuk memproduksi kemasan umum. Kreatifitas hampir tidak diperlukan karena hanya menggunakan contoh yang sudah diberikan, material yang digunakan sangat sederhana misalnya terbatas karton dan kertas pelapis yang dibuat secara teknik manual. Penggunaan material dan alat baru dapat menjadi pengetahuan bagi pengrajin Kampung Ampera untuk memperkenalkan kemasan dengan siluet yang familiar namun bersiap untuk beradaptasi dengan kondisi beragam yang ada di kompetisi pasar di era Revolusi Industri 4.0 ini. Fabrikasi material transparan sering digunakan dibidang arsitektur sehingga memungkinkan menyelenggarakan sebuah kegiatan pengkayaan intelektual dan keterampilan dengan tingkatan lebih lanjut (Oestigaard, 2004) kepada pengrajin Kampung Ampera. Kegiatan pengabdian kepada masyarakat ini janganlah terhenti pada pengetahuan bersifat teori, sebuah keberlanjutan perlu secara nyata diimplementasikan secara terus-menerus agar pengrajin makin fasih dan dapat meningkatkan nilai guna dan jual produk mereka (ZabalaIturriagagoitia, 2012). PKM UNTAR mencetuskan ide dan teknik fabrikasi yang cocok untuk pengrajin kampung Ampera. Melalui komunikasi dan negosiasi dengan workshop yang memproduksi kemasan lebih kompleks. Sketsa dapat dikembangkan dengan proses pemilihan bahan termasuk teknologi tergolong asing namun dapat diaplikasikan oleh oleh kelompok pengrajin.

Kegiatan Pengabdian Kepada Masyarakat ini menghasilkan keluaran berupa sketsa perencanaan, material board, sampel-sampel material dan transformasi kemasan, termasuk proses yang akan didokumentasikan dengan foto dan pemotretan akhir sebagai keluaran yang dapat dipublikasikan. Proses eksperimentasi menghasilkan tahapan melalui langkah-langkah berbeda, sehingga tahapan yang diturunkan kepada pengrajin kampung Ampera adalah kompilasi langkah tersingkat dan paling efektif yang sudah melalui uji coba sebelumnya. Sketsa memberikan gambaran perencanaan umum, material yang terpotong ditempel dan disatukan oleh pengrajin menjadi prototipe 1:1. Kelompok pengrajin dapat berinteraksi langsung dengan mesin, aksesoris saat pengerjaan hasil akhir. Prototype akan diturunkan dan dimodifikasi, sesuai arahan perancang, difoto secara profesional untuk kepentingan publikasi demi kepentingan bersama. 


\section{METODE PENELITIAN}

Dengan metode eksperimentasi material, sketsa rancangan dikembangkan melalui serangkaian tes terhadap beberapa material arsitektural berkarakter transparan atau translusen. Beberapa metode untuk memfabrikasi material dengan karakter tersebut diuji coba oleh tim PKM UNTAR, sebelum memutuskan jenis material dan metode fabrikasi yang paling cocok. Adapun langkah-langkah dalam membuat percobaan kemasan ini adalah sebagai berikut:

a. Membuat sketsa kemudian diuji coba dengan membuat kardus untuk diketahui komposisinya

b. Membuat pola di akrilik, di potong, bagian fillet di bending, di rakit dan terakhir di lem.

c. Hasil jadi merupakan prototype untuk diproduksi masal.

Fokus pengembangan fabrikasi kemasan arsitektural menekankan karakter:

a. Pengembangan Bahan Kerajinan Baru

Bahan kemasan untuk konsep transparansi Soiree mengembangkan akrilik sebagai bahan utama. Kalkir, kertas roti, hvs adalah alat kerja yang umum digunakan oleh kelompok pengrajin. Selain itu kertas dan karton dijadikan sebagai media dalam sketsa prototipe manual, sebelum dijadikan sample akhir. Untuk kebutuhan visualisasi dan penjelas teori, foto, dokumen, kasus akan dipresentasikan agar memudahkan pengrajin membayangkan keterhubungan konsep kepada keluaran.

Untuk memudahkan proses turunan, penjelasan dan sketsa akan disertakan sebagai contoh sehingga pengerjaan material dan pemotongan akan dapat menghemat waktu dan bahan, sebelum pengrajin siap menerjemahkan konsep menjadi keluaran akhir berupa kemasan aksesoris. Akrilik dipotong dengan mesin potong, dibending dengan pemanas. Hasil potongan dijalin dan digabung dengan material lain menggunakan teknik manual yang dikuasai pengrajin (Gerritsen \& Riello, 2014). Perpaduan bahan dan teknik yang dihasilkan secara manual dan mesin diharapkan dapat menjadi terobosan bagi pengrajin Kampung Ampera. Meski membuat kemasan jenis ini akan memakan biaya lebih tinggi, namun bila diproduksi massal selain menghemat waktu dan tenaga kualitas finishing dan harga dapat ditingkatkan melalui produktifitas dan efektivitas.

\section{b. Prototipe}

Ukuran kemasan diukur secara spesifik pada aksesoris perancang busana, sehingga menghasilkan desain yang tailor -fitted. Pembuatan prototipe mengalami dua fase utama yakni sample dan prototipe. Setelah merampungkan prototipe akhir, prototipe dirampungkan sebagai sebuah keluaran final. Dengan mengandalkan quality control dari pihak perancang, prototipe akan diproduksi secara terbatas dan difilter untuk pameran dan dipresentasikan sebagai produk siap jual. Kemasan bersama dengan aksesorinya akan ditawarkan kepada media dan khalayak sebagai pemenuhan target pasar sesungguhnya. Prototipe yang dihasilkan pada PKM, hanya ditujukan sebagai draft kerja, diselesaikan sebagai contoh proyek dengan tujuan akhir untuk kepentingan bersifat edukasional bagi kelompok pengrajin (Ravasi \& Stigliani, 2012).

\section{c. Teknik Fabrikasi Arsitektural}

Metode eksperimental arsitektur sesungguhnya bukan metode baru dibidang arsitektur dan perancangan sistematik dapat disusun bertumpuk sehingga menghasilkan volume tiga dimensi. Namun demikian teknik eksperimental arsitektur sering kali dianggap kurang produktif karena bergantung pada proses dan kondisi, material perlu dites berkali - kali untuk mendapatkan hasil diinginkan. Meski memegang teori, pada kenyataan percobaan mengandalkan eksperimentasi bergantung kepada banyak faktor, intuisipun dibutuhkan untuk menghasilkan produk keluaran yang memenuhi harapan. 


\section{HASIL DAN PEMBAHASAN}

Kemasan dibuat dengan mengedepankan ide transparansi untuk mewadahi aksesori fashion. Tujuan dibuatnya kemasan dengan bertekstur transparan adalah untuk menonjolkan karya buatan perancang, tanpa kehilangan kemampuang tektonik pengrajin. Dimulai dengan sketsa sederhana, packaging direncanakan menggunakan material akrilik transparen yang diuji coba dulu dengan kardus.

Langkah-langkah dalam membuat percobaan kemasan ini adalah sebagai berikut:

a. Membuat sketsa kemudian diuji coba dengan membuat kardus untuk diketahui komposisinya. Kemasan dibuat dengan mengedepankan ide transparansi untuk mewadahi aksesori fashion. Tujuan dibuatnya kemasan dengan bertekstur transparan adalah untuk menonjolkan karya buatan perancang, tanpa kehilangan kemampuan gaya tektonik pengrajin. Dimulai dengan sketsa sederhana (lihat Gambar 1), packaging direncanakan menggunakan material akrilik transparan yang diuji coba dulu dengan kardus. Kemasan merupakan nilai tambah dari produk untuk mempengaruhi economic performance (Surbakti, 2013)

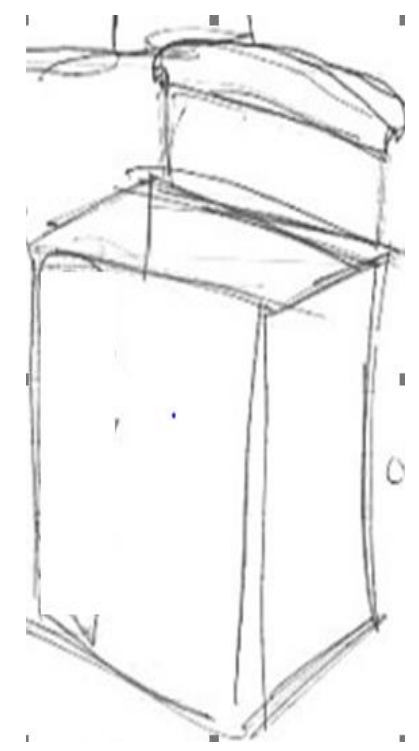

Gambar 1. Sketsa sederhana

Sumber: Tim PKM, 2018

b. Membuat pola di akrilik, di potong, bagian fillet di bending, di rakit dan terakhir di lem (Gambar 2). Proporsi yang sudah sesuai dengan yang diharapkan digambarkan polanya sehingga akrilik dapat dipotong dengan mesin potong. Kemudian diamplas secara manual oleh pengrajin agar menghasilkan sisi yang rapih dan tidak tajam. Bagian fillet di bending dengan mesin pemanas dengan diameter $0.5 \mathrm{~cm}$ sehingga menghasilkan lengkungan yang halus sesuai dengan keinginan. Hasil yang telah jadi di rakit oleh pengrajin dan di lem dengan pelekat akrilik sehingga kuat tanpa meninggalkan noda yang berarti. 

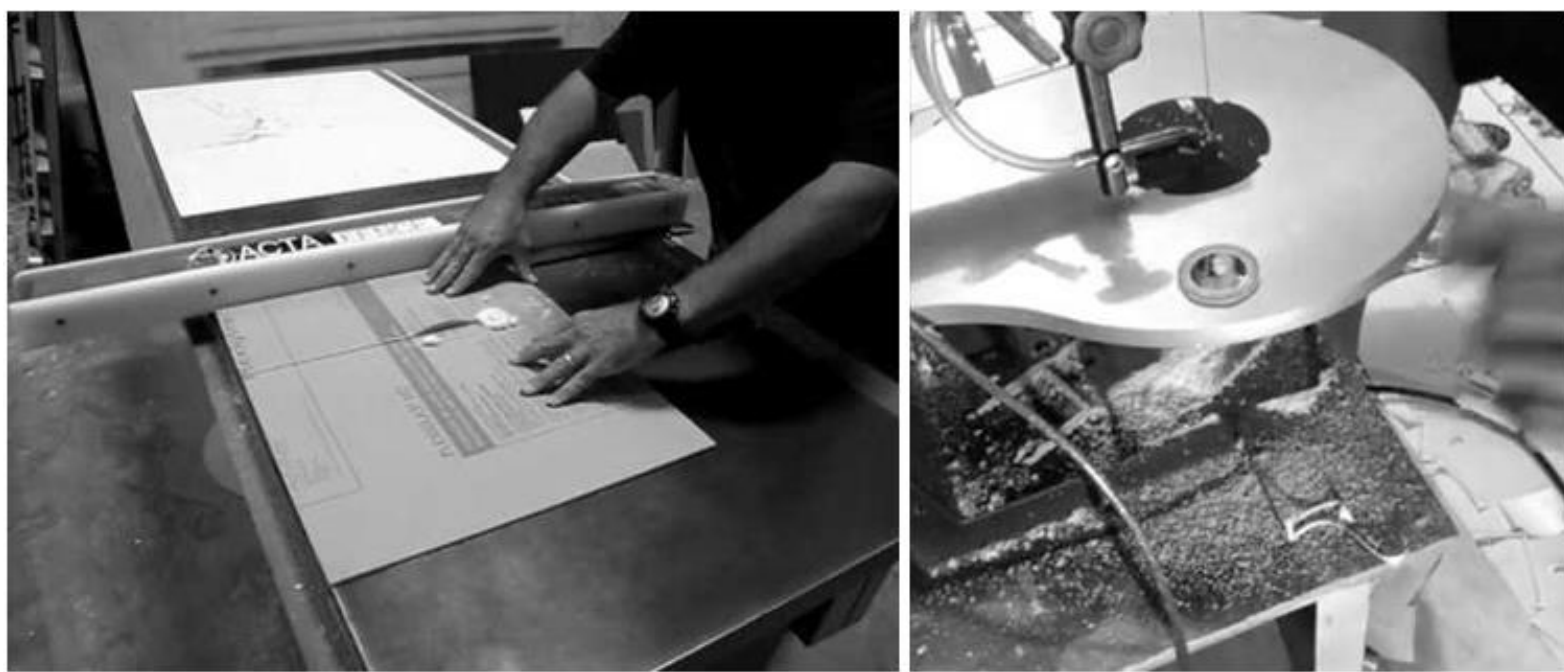

Gambar 2. Proses potong akrilik

Sumber: Tim PKM, 2018

c. Hasil jadi merupakan prototype untuk diproduksi masal.

Kemasan yang telah jadi dibersihkan dan dijadikan prototype untuk diproduksi massal. Kemasan menghasilkan sisi yang jernih sehingga tautan yang berada ditengah dapat menyangga aksesoris dan menonjolkan letak aksesori yang seolah melayang.

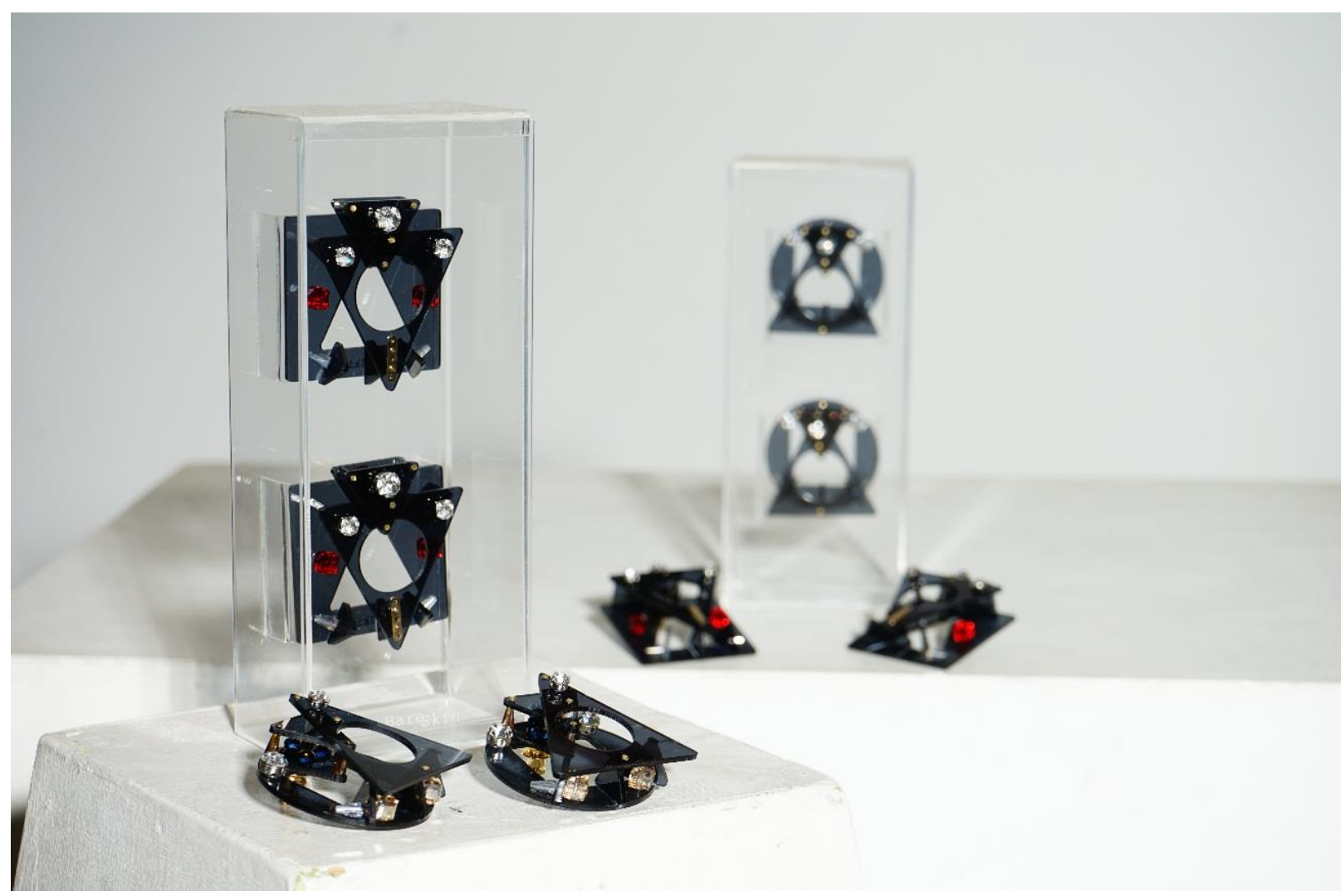

Gambar 3. Foto Produk Kemasan Final

Sumber: Kemasan oleh Tim PKM 2018, Aksesori sample oleh Bareskin

Dengan adanya produk kemasan final (Gambar 3) ini diharapkan memberikan Economic Value Added (EVA) dari produk barang utama yaitu produk aksesori, sehingga penampilan dari produk 
aksesori ini menjadi menarik, dengan adanya ketertarikan dari pengamat ini untuk membeli produk, akan terjadi proses saling menguntungkan dan membutuhkan antara produk keemasan dan produk aksesori yang sesuai dengan konsep Symbiosis. Konsep symbiosis adalah konsep yang saling menguntungkan. Konsep ini dikembangkan oleh Kisho Kurokawa (1991, 1994), konsep ini merupakan pengembangan dari konsep Kenzo Tange yaitu metabolism, yang berarti konsep pengembangan baik skala kota maupun bangunan. Konsep hybrid merupakan pegembangan dari konsep symbiosis agar penggunaannya dapat dimanfaatkan secara optimal. Konsep hybrid (Per, Mozas \& Arpa, 2014) adalah konsep hubungan saling menguntungkan dari kegiatan yang berlawanan (Trisno \& Lianto, 2018).

\section{KESIMPULAN DAN SARAN}

Kegiatan pengabdian pada masyarakat ini menghasilkan kemasan aksesori arsitektural dengan mengkombinasikan teknik manual dan penggambaran cad untuk menghasilkan perhitungan yang presisi bagi pola kemasan. Kemasan dibentuk dengan mesin potong, laser cutting dan bending sehingga menghasilkan kemasan transparan yang menonjolkan aksesori yang dijual. Pengrajin mendapatkan kesempatan untuk menjual kemasan termasuk aksesorinya di acara Soiree dan mendapatkan tanggapan yang baik sehingga meningkatkan penjualan pengerajin dan juga kemampuannya, namun juga meningkatkan pendapatan mereka. Kemasan ini mendapat tanggapan positif dan dijual di acara Soiree, aksesori hanya merupakan sample untuk keperluan fotografi, aksesoris ini dipinjam dari Bareskin, Bareskin adalah sebuah nama dari perusahaan yang memproduksi dan mempromosikan hasil PKM yang menjadi rekanan penulis.

Temuan dalam penelitian ini adalah memberikan pengetahuan pengerajin Kampung Ampera untuk meningkatkan sumber daya manusia, untuk siap menghadapi kemajuan teknologi terutama teknologi keemasan dengan menggunakan material keemasan akrilik transparan, dengan mengkombinasikan teknik manual dan penggambaran cad untuk membuat keemasan dengan presisi dan akurat, sehingga siap mengikuti perkembangan dari Revolution Industry 4.0.

\section{Ucapan Terima Kasih}

Terima kasih kepada pihak Kelompok Pengrajin Kampung Ampera, Bareskin dan Direktorat Penelitian dan Pengabdian Kepada Masyarakat Universitas Tarumanagara yang telah memfasilitasi hingga terlaksananya kegiatan PKM ini.

\section{REFERENSI}

Bloch, P. H. (2011). Product Design and Marketing: Reflections After Fifteen Years. J Prod Innovation Management, 28, pp. 378-380.

Doğan, C. (2012) Product Design for Sustainablility: Development of a New Graduate Course in Industrial Design. METU JFA, 2, pp. 313-329.

Gerritsen, A. \& Riello, G. (2014). Writing Material Culture History, New York: Bloomsbury Publishing.

Grassby, R. (2005). Material Culture and Cultural History. Journal of Interdisiplinary History xxxv, pp. 591-603.

Oestigaard, T. (2004) Approaching Material Culture: A History of Changing epistemologies. Journal of Nordic Archaelogical Science 14, pp. 79-87.

Per, A. F., Mozas, J. Arpa, J. (2014). This is Hybrid: An Analysis of Mixed-Use Buildings. Spain: A + T Architecture Publishers. 
Ravasi D. \& Stigliani, I. (2012). Organizing Thoughts and Connecting Brains: Material Practices and the Transition From Individual to Group-Level Prospective Sensemaking. The Academy of Management Journal, 55, pp.1232-1259

Surbakti, A. A. (2013). Pengaruh Manajemen Mutu Pada Tahap Pelaksanaan Konstruksi. Bandung: Universitas Katolik Parahyangan.

Trisno, R. \& Lianto, F. (2018). Realization of Hybrid Concept and Symbiosis in Green Open Space (RTH) at Housing Complex RW (Neighborhood Councils) Pluit, Jakarta Utara, Indonesia. Journal of Physics: Coference Series, 1179, pp. 1-6. Diunduh dari: https://iopscience.iop.org/article/10.1088/1742-6596/1179/1/012165/meta

Zabala-Iturriagagoitia, J. M. (2012). New Product Development in Traditional Industries: Decision-Making Revised. Journal of Technology Management \& Innovation, 7(1), pp. 31-51 